\title{
The Volta Basin Water Allocation System: assessing the impact of small-scale reservoir development on the water resources of the Volta basin, West Africa
}

\author{
C. Leemhuis ${ }^{1}$, G. Jung ${ }^{2, *}$, R. Kasei ${ }^{1}$, and J. Liebe ${ }^{1}$ \\ ${ }^{1}$ Center for Development Research, Walter-Flex-Strasse 3, Bonn, Germany \\ ${ }^{2}$ Institute for Meteorology and Climate Research, Karlsruhe Institute of Technology, Garmisch-Partenkirchen, Germany \\ * now at: C.N.R. Institute for Atmospheric Pollution, Division of Rende, Italy
}

Received: 15 January 2009 - Revised: 25 March 2009 - Accepted: 28 April 2009 - Published: 11 August 2009

\begin{abstract}
In the Volta Basin, infrastructure watershed development with respect to the impact of climate conditions is hotly debated due to the lack of adequate tools to model the consequences of such development. There is an ongoing debate on the impact of further development of small and medium scale reservoirs on the water level of Lake Volta, which is essential for hydropower generation at the Akosombo power plant. The GLOWA Volta Project (GVP) has developed a Volta Basin Water Allocation System (VBWAS), a decision support tool that allows assessing the impact of infrastructure development in the basin on the availability of current and future water resources, given the current or future climate conditions. The simulated historic and future discharge time series of the joint climate-hydrological modeling approach (MM5/WaSiM-ETH) serve as input data for a river basin management model (MIKE BASIN). MIKE BASIN uses a network approach, and allows fast simulations of water allocation and of the consequences of different development scenarios on the available water resources. The impact of the expansion of small and medium scale reservoirs on the stored volume of Lake Volta has been quantified and assessed in comparison with the impact of climate variability on the water resources of the basin.
\end{abstract}

\section{Introduction}

The Volta Basin drains an area of approx. $400000 \mathrm{~km}^{2}$ of the subhumid to semiarid West-African savannah zone. The

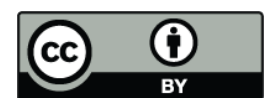

Correspondence to: C. Leemhuis (leemhuis@uni-bonn.de) basin is shared by six riparian nations. Burkina Faso occupies vast upstream areas (43\%), Ghana covers large downstream areas $(42 \%)$, and the remainder is shared by Togo, Côte d'Ivoire, Mali and Benin (Fig. 1). The annual areal basin precipitation averages around $1000 \mathrm{~mm}$, but shows a steep south $(>2000 \mathrm{~mm})$ to north $(<500 \mathrm{~mm})$ gradient. Precipitation patterns are characterized by a high spatial and temporal variability.

In 1964 the Volta was dammed in the lower reach of the basin at Akosombo in southern Ghana, creating Lake Volta mainly for hydropower generation. The artificial reservoir has a total storage volume of $148 \mathrm{~km}^{3}$ and a live storage volume of $60 \mathrm{~km}^{3}$ with a mean 2-3 years regeneration period. The relatively cheap hydropower generated at the dam is an important driver for the development of the Ghanaian economy.

During the 1980s, West Africa experienced a dramatic drought period which lead to water scarcity, food shortages and hunger. The low water levels in Lake Volta eventually lead to power shortages in 1984, and the storage of Lake Volta did not recover completely since.

Also the population of the Volta Basin was severely affected by this sequence of drought years. As a consequence, the small and medium scale reservoir potential was developed to secure irrigation, live stock and household water availability for the rural societies of northern Ghana and Burkina Faso during the dry season. The reservoirs mainly supply village-level schemes with imperfect hydraulic control (Van de Giesen et al., 2001). Burkina Faso is one of the West African countries with the highest density of small reservoirs, and the demand for further reservoirs still remains. In Burkina Faso, 1053 small and medium scale

Published by Copernicus Publications on behalf of the European Geosciences Union. 

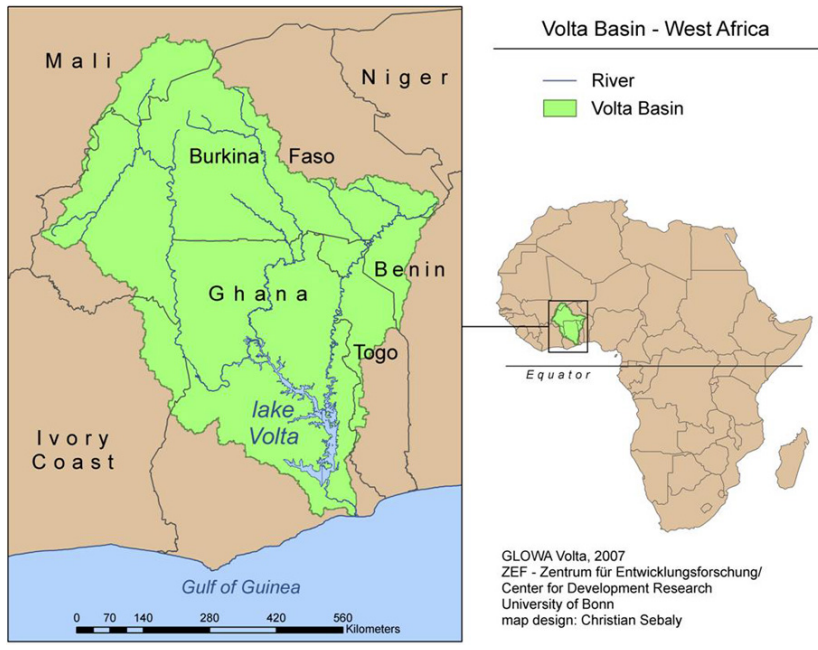

Fig. 1. Location map of the Volta River Basin.

reservoirs are registered. Half of them were constructed between 1974 and 1987, which coincides with the dramatic drought period in the early eighties of the last century (Cecchi, 2008). Also northern Ghana suffered during the above mentioned drought period, resulting in the construction of small and medium scale reservoirs to date.

On a transboundary context, the development of small and medium scale reservoirs in the northern and central basin is easily blamed every time the water level of Lake Volta drops to a critical level. However, due to spatial and temporal precipitation variability of the Volta basin the total yearly inflow to Lake Volta is highly variable. Therefore climate variability could also be accused being the main cause for critical water levels of the reservoir.

For an objective discussion on the problem issue a quantitative analysis of the main drivers that generate erratic yearly inflows to Lake Volta is required. This paper analyses the main drivers for erratic annual inflows into Lake Volta, and discusses the results of an integrated small and medium scale reservoir impact analysis. The analysis is done with a quantitative water allocation model for the Volta basin that has been developed within the framework of the interdisciplinary GLOWA Volta project (http://www.glowa-volta.de).

\section{Methodology}

\subsection{The Volta Basin Water Allocation System (VB-WAS)}

The Volta Basin Water Allocation System (VB-WAS) is a decision support tool that allows incorporating the impact of possible future climate conditions and projected water demand scenarios on future water resources management and infrastructure development in the basin. VB-WAS (Fig. 2) simulates the impact of various water users (water demand)

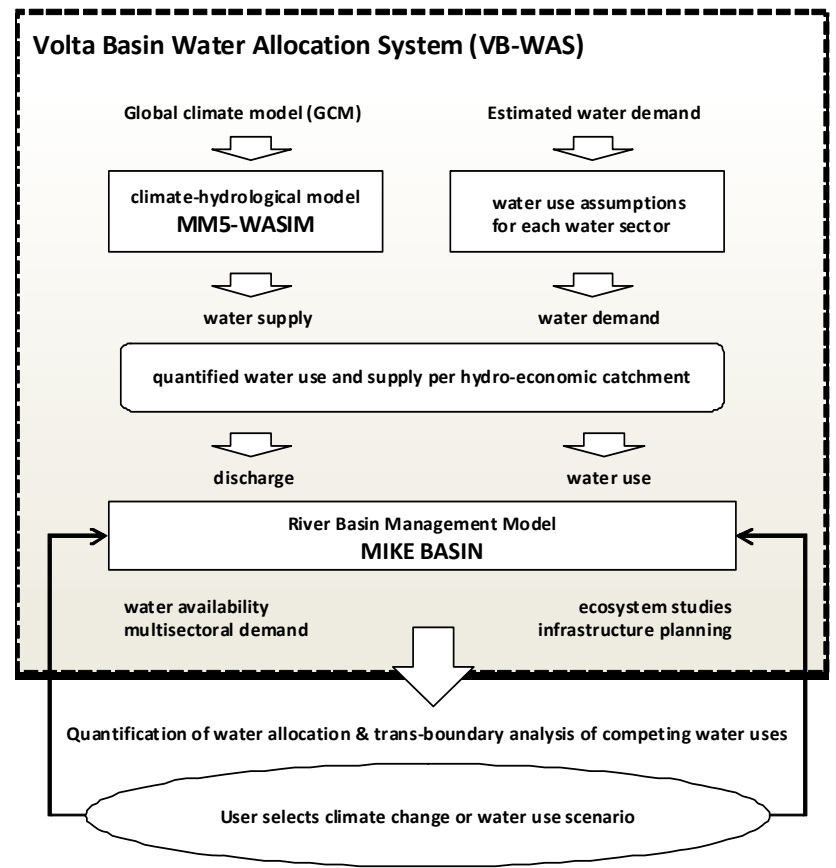

Fig. 2. Structure of the Volta Basin Water Allocation System (VBWAS).

on the water allocation (water supply) within the Volta Basin using a sequence of data coupled and fully coupled models (http://www.glowa-volta.de).

VB-WAS is a joint modeling approach that combines the river basin management model Mike Basin (Danish Institute of Hydrology, 2003), which allows fast simulations of water allocation using a network approach, and the 1-way coupling simulation results of the MM5/WaSiM-ETH climatehydrological joint modeling approach, providing spatial and temporal distributed input for water supply. The simulation results of the spatially distributed and process based hydrological model WASIM-ETH account for the physical discharge variability of the Volta basin.

\subsection{Computing water demand and water supply}

The Water Balance Simulation Model WASIM-ETH is a process based spatially distributed hydrological model that was applied to the Volta Basin with a $1 \mathrm{~km} \times 1 \mathrm{~km}$ spatial and daily temporal resolution (Jung, 2006). The model was calibrated for the years 1962-1969, but continuous daily observational discharge data was available only for the hydrological year 1968/1969. Thereafter the model was run on two time slices (1991-2000 and 2030-2039) of an ECHAM4 simulation, running the IPCC scenario IS92a (IPPC, 2001), which were dynamically downscaled with the regional climate model MM5 to a $9 \mathrm{~km} \times 9 \mathrm{~km}$ spatial resolution (Jung and Kunstmann, 2007). The IS92a scenario assumes an annual increase in atmospheric $\mathrm{CO}^{2}$-content of $1 \%$ starting in 1990. 
The set up of the joint climate-hydrological modeling application MM5/WASIM-ETH for the Volta Basin does not include the anthropogenic water demand of the various water resources users. It purely simulates the physical hydrology of the Volta basin and does not take into account the numerous demand sides, such as reservoirs for hydropower generation or irrigation schemes, or surface water withdrawals from the rivers. Furthermore the model set up does not consider the hydrological impact of numerous small and medium size reservoirs that are scattered throughout Burkina Faso and northern Ghana. In order to account for the above mentioned water abstractions and different national water policies of the Volta basins main riparian states, Ghana and Burkina Faso, the VB-WAS model set up for Mike Basin was delineated into 23 hydro-economic catchments with respect to national borders and the location of large scale reservoirs. At the outlet of each hydro-economic catchment, water was abstracted from different water-users.

The VB-WAS model set up distinguishes between the following water demands or uses of surface water: small and medium scale reservoir abstraction, surface water withdrawal from the river, large scale irrigation abstraction and nonconsumptive water use for hydropower generation (Table 1). The water abstraction rates of the specific water users at each catchment were based on certain simplified assumptions.

The water demand of small and medium size reservoirs located within one hydro-economic catchment is integrated by lumping their storage volumes into one total storage value. We have assumed that the reservoirs captured surface runoff at the beginning of the rainy season over the course of the month of June. All additional inflow that was generated during the continuous rainy season (June-September) overflows the reservoir. During the dry season (October-May) the complete reservoir storage was consumed without any additional inflow to the reservoir. Evaporation losses of the reservoir were accounted according to potential evapotranspiration time series generated by WASIM-ETH using the Penman approach for land cover type "water" and the maximum total surface area. Reductions in evapotranspiration rates due to the volume-area relationship have not been considered. This implies a slight overestimation of the annual reservoir evaporation rates. Surface water withdrawals from the river for household use per hydro-economic-catchment were computed with respect to population density, water use per capita per day, and the share of people that has access to save drinking water resources (United Nations Development Program, 2007). Water usage for large scale irrigation and turbine flow for hydropower generation are based on secondary data from the responsible reservoir authorities.

The spatial corresponding specific discharge time series $(\mathrm{mm})$ simulated with the joint modeling application MM5/WASIM-ETH was fed as specific discharge (mm) for each hydro-economic catchment of the Mike Basin model. Mike Basin calculates the total runoff $\left(\mathrm{m}^{3} / \mathrm{s}\right)$ for every hydroeconomic catchment and the inflow $\left(\mathrm{m}^{3} / \mathrm{s}\right)$ from the head-

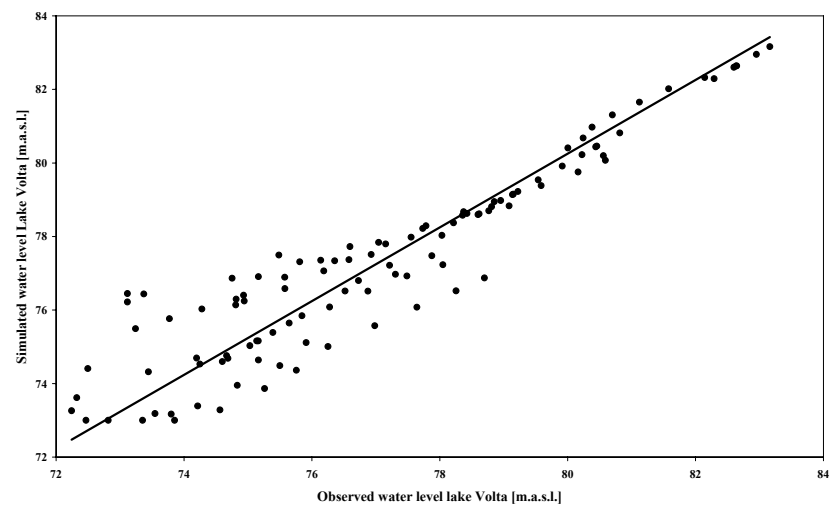

Fig. 3. Scatter plot of observed versus simulated water level [m.a.s.1.] of Lake Volta for the validation period 1992-2000. The model efficiency reaches $R^{2}=0.85$.

water catchment. This data coupling allows a spatially distributed representation of discharge variability at each hydroeconomic catchment of the VB-WAS model, and accounts for the spatial and temporal discharge variability within the Volta Basin. The water storage and hence the water level of the large reservoirs is computed with the Mike Basin model according to the reservoir parameters and operation rules that have been parameterized for the VB-WAS model.

\subsection{Validation of the VB-WAS model}

The WASIM-ETH model for the Volta Basin used for 1-way data coupling in the VB-WAS model has been calibrated and validated by Jung (2006). The assumptions that have been made for the water demands of each hydro-economic catchment were based on water use assumptions and therefore do not imply the adjustment of any calibration parameter. The MM5 generated data for climate input of the WASIMETH model was validated with observed climate data (Jung, 2006). The MM5 simulated climate data time series do not represent the meteorology of the real years and therefore the simulation results of the VB-WAS model can not be validated with the usual procedure. However, in order to assess the performance of the VB-WAS model the simulation period 1992-2000 was used as validation period. The water level of Lake Volta serves as an aggregated indicator for the performance of the VB-WAS model simulation. Figure 3 displays the scatter plot of observed versus simulated water level of Lake Volta for the period 1992-2000 on a mean monthly spatial resolution. The achieved model efficiency of $R^{2}=0.85$ indicates a good performance of the VB-WAS model which can then be further used for scenario analysis. 
Table 1. List of water demand calculation per hydro-economic catchment for the VB-WAS model.

\begin{tabular}{|c|c|}
\hline VB-WAS water user & VB-WAS catchment water demand assumption \\
\hline small and medium scale reservoirs & $\begin{array}{l}\text { lumped reservoir storage abstracted at the beginning of the rainy season in June; } \\
\text { slight overestimation of evaporation losses }\end{array}$ \\
\hline surface water withdrawal & regulated by population density, water use per capita per day and access to save water resources \\
\hline big scale irrigation scheme & recorded data from SONABEL (Burkina Faso) \\
\hline turbine flow hydropower & recorded data from Volta River Authority (Ghana) and SONABEL (Burkina Faso) \\
\hline
\end{tabular}

\section{Scenario set up}

\subsection{Reservoir storage evaluation and scenario set up}

An inventory of all registered small and medium scale reservoirs in Burkina Faso (International Institute for Water and Environmental Engineering, 2006) represents the basis for the water use application of the hydro-economic catchments that are located in Burkina Faso. The total maximum storage volume of all registered small and medium scale reservoirs located within the water divide of the Volta Basin of Burkina Faso amounts to $670 \times 10^{6} \mathrm{~m}^{3}$. For Ghana such an inventory does not yet exist. As an approximation for small and medium size reservoir storage, we have used area based storage volume estimates. Forkour (2006) has mapped the surface areas of small and medium scale reservoirs in Ghana from Landsat ETM+ data. The area-volume function is based on an extensive bathymetrical survey that was conducted on 64 small reservoirs in the Upper East Region of Ghana (Liebe et al., 2005). A comparative study by Annor et al. (2009) verifies this relationship. The total maximum storage volume of all detected small and medium scale reservoirs with the applied storage calculation that are located within the water divide of the Volta Basin of Ghana amounts to $120 \times 10^{6} \mathrm{~m}^{3}$. For the remaining riparian countries of the Volta Basin Mali, Togo, Benin and Côte d'Ivoire we do not have any access to information on large, medium and small reservoirs, but assume that the influence is rather insignificant.

To assess the impact of the small and medium size reservoirs of Burkina Faso and Northern Ghana on the water levels of Lake Volta, we have set up a variety of scenarios and compared it with a baseline simulation for the period 19922000 , for which the above mentioned reservoir volume has been implemented. Scenario A assumes that there has been reservoir development only in Burkina Faso, but not in northern Ghana. Scenario B assumes that there has been no reservoir development in the entire Volta Basin. This historical reservoir scenario application Scenario A and Scenario B allows an assessment of the impact of all existing small and medium scale reservoirs on a national scale excluding imprecise estimates for future reservoir development.

\subsection{Consecutive dry year's scenario}

The simulated areal precipitation data of the joint model approach MM5/WASIM-ETH for the time slice 1991-2000 has been classified into five climate categories ranging from wet, below average, and average to above average and dry years. The classification is based on the computation of the Standardized Precipitation Index (SPI) by McKnee (1993) for a 40 year time series (1965-2005) of observed precipitation data for the Volta Basin. With the typical climate years, the effect of various combinations of wet, average and dry years can be evaluated, or historic climate can be roughly replicated.

For the drought climate scenario we have defined a time series with two consecutive dry years following a sequence of three below average years. This was based on the replication of the historic time slice 1992-2000, but the above average year 1996 and the average year 1997 were replaced by dry years. For Scenario $\mathrm{C}$ we apply the drought climate scenario for water supply input of each hydro-economic catchment and combine it with Scenario B assuming that there has been no reservoir development in the entire Volta Basin.

\section{Results and conclusions}

\subsection{Small and medium scale reservoir national historic scenario}

The simulated water level of the historical small and medium scale reservoir Scenario A for the time slice 1992-2000 indicates an overall minor impact of the small and medium scale reservoir development in Northern Ghana on the storage volume of Lake Volta compared to the simulated water level of the baseline simulation. Whereas the simulated water level of the historical small and medium scale reservoir Scenario B for the time slice 1992-2000 shows a more considerable impact of the small and medium scale reservoir development in the Volta Basin on the storage volume of Lake Volta compared to the simulated water level of the baseline simulation. As shown in Fig. 4 the impact on the stored volume of Lake Volta for Scenario A and B accumulates over the eight year simulation period. On an eight year total sum the loss of storage amounts to $6.1 \mathrm{~km}^{3}$ for the entire Volta basin, and $1.1 \mathrm{~km}^{3}$ respectively for Ghana over the simulated time slice 


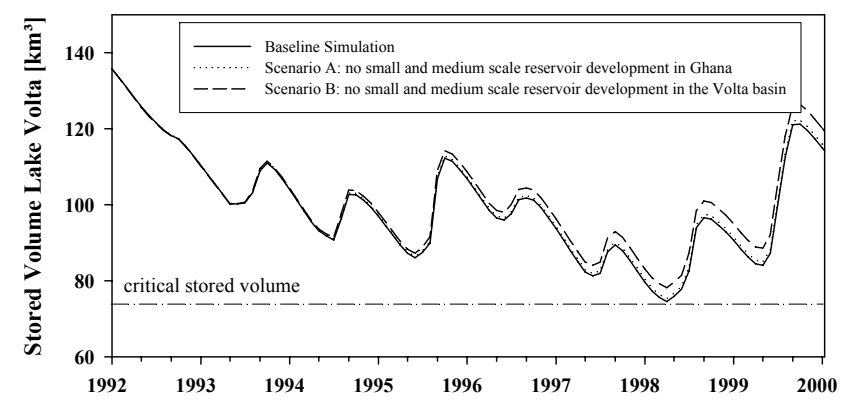

Fig. 4. Lake Volta stored volume $\left[\mathrm{km}^{3}\right]$ hydrograph for the baseline simulation, scenario A with no small and medium scale reservoir development in Ghana and scenario B with no small and medium scale reservoir development in the Volta basin for the simulation period 1992-2000. The dashed line indicates the critical stored volume of Lake Volta, where the turbines have to reduce their full capacity.

1992-2000 with an increasing storage loss over the entire time period. This accumulation effect of storage loss is related to two independent processes: a) the small and medium scale reservoir storage capacity itself expanded from $0.7 \mathrm{~km}^{3}$ to $0.79 \mathrm{~km}^{3}$ over the time span $1992-2000$ and b) the storage losses of Lake Volta increased by time with every abstraction of water for the yearly inundation of the small and medium scale reservoirs of the basin.

\subsection{Consecutive dry year's scenario}

The consecutive dry year's scenario for the time slice 19922000 clearly shows the strong impact of climate variability on the stored Volume of Lake Volta. For the simulated time slice the annual total inflow to Lake Volta fluctuated between 11 to $59 \mathrm{~km}^{3}$. The comparison of the stored volume time series of Scenario B (without small and medium scale reservoir development in the Volta basin) and Scenario B in combination with a consecutive dry year's scenario (Fig. 5) demonstrates the approximate impact of climate variability on the stored volume of Lake Volta. The simulation of the stored volume time series for Scenario C describes the decline of the water level of Lake Volta from the beginning of the rainy season in June 1996 until it reaches the critical water level for the generation of hydropower at full capacity in April 1997. The storage of Lake Volta starts to recover in the early rainy season in 1998 but does not reach the stored volume of Scenario $B$ at the end of the simulation period. In September 1997, the storage loss of Lake Volta due to the two consecutive dry years reaches its maximum of $18.6 \mathrm{~km}^{3}$.

\section{Summary and discussion}

The scenario analysis has shown that the VB-WAS model allows quantifying the impact of the small and medium scale reservoir development on the stored volume of Lake Volta

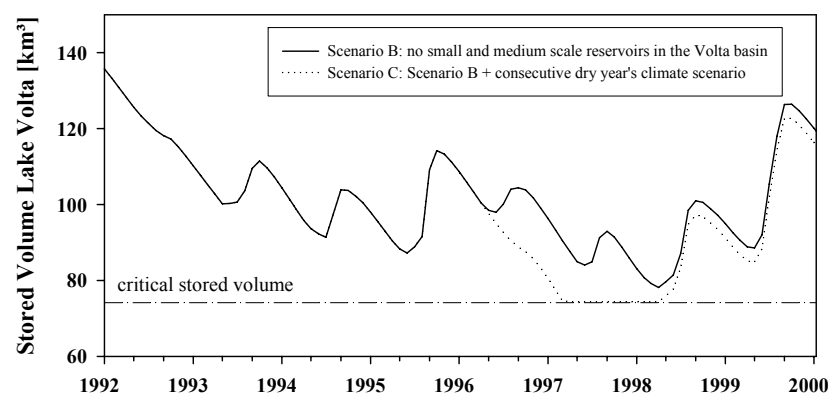

Fig. 5. Lake Volta stored volume $\left[\mathrm{km}^{3}\right]$ hydrograph for Scenario $\mathrm{B}$ with no small and medium scale reservoir development in the Volta basin and Scenario C with Scenario B plus a consecutive dry year's scenario for the simulation period 1992-2000. The dashed line indicates the critical stored volume of Lake Volta, where the turbines have to reduce their full capacity.

and correspondingly on the hydropower capacity of the Akosombo dam. According to the VB-WAS set up we have to critically question if the filling period for the small and medium scale reservoirs in general is too short to concentrate it within the month of June. Looking at the discharge time series of the applied period 1992-2000 there was always enough catchment discharge to fill the storage during the month of June, but to be able to include severe dry years for the analysis, the filling period should be expanded to the period of June and July. If we compare the loss of storage of Lake Volta over a period of eight years with the loss of storage due to climate variability like e.g. a sequence of two consecutive dry years we can conclude that the impact of the reservoir development on the water resources of the Volta basin is marginal compared to their benefits in securing food production and livestock during the dry season. However, the accumulation effect of Lake Volta storage loss already was initiated when the small and medium scale reservoir development in Burkina Faso and northern Ghana started in the early seventies of the last century. If we then compare the mean annual storage losses of the small and medium scale reservoirs with the mean annual difference between evaporation and rainfall over the lake, which amounts to $2.3 \mathrm{~km}^{3}$ (Andreini et al., 2000) we can demonstrate that the evaporation losses of Lake Volta are three times higher than the mean annual storage losses due to small and medium scale reservoir development. Taylor et al. (2006) state that, at present, no comprehensive hydrological model exists that represents the entire Volta Basin and could be used to improve water management communication between the riparian nations of Ghana and Burkina Faso. The VB-WAS model has proven to be a powerful tool for the assessment of the impact of infrastructural development like small and medium scale reservoir development, and climate variability on the water resources of the Volta Basin. The model helps to improve communication on transboundary water management, like e.g. the development of small and medium scale reservoirs in Burkina 
Faso by quantifying the impact on the storage of Lake Volta under different climate conditions.

Acknowledgements. We gratefully acknowledge financial support of the Federal Ministry of Education and Research (BMBF) as main sponsor of the GLOWA-Volta project.

Edited by: B. Schmalz, K. Bieger, and N. Fohrer

Reviewed by: two anonymous referees

\section{References}

Andreini, M., van de Giesen, N., van Edig, A., Fosu, M., and Andah, W.: Volta Basin Water Balance, ZEF-Discussion Paper on Development Policy, Number 21, 2000.

Annor, F. A., van de Giesen N., Liebe, J., van de Zaag, P., Tilmant, A., and Odai, S. N.: Delineation of small reservoirs using radar imagery in a semi-arid environment: A case study in the Upper East Region of Ghana, Phys. Chem. Earth, 34(4-5), 309-315, 2009

Cecchi, P.: Towards an Atlas of Lakes and Reservoirs in Burkina Faso, SRP Tool Kit Working Paper, 2008.

Danish Institute of Hydrology: MIKE BASIN. A versatile decision support tool for integrated water resources management and planning, DHI Water and Environment, Denmark, 2003.

Forkour, G.: Modelling the optimum areas for constructing small reservoirs in Ghana, Msc. Thesis, University College London (UCL), 18-40, 2006.

International Institute for Water and Environnemental Engineering: Retenues d'eau au Burkina Faso, Version 2.0, 2006.
IPPC: Climate Change 2001: The Scientific Basis, 2001.

Jung, G.: Regional Climate Change and the Impact on Hydrology in the Volta Basin of West Africa, Institut für Meteorologie und Klimaforschung (IMK-IFU), 41-90, 2006.

Jung, G. and Kunstmann, H.: High resolution regional climate modeling for the Volta region of West Africa, Journal of Geophysical Research, 112, D23108, doi:10.1029/2006JD007951, 2007.

Kunstmann, H. and Jung, G.: Impact of regional climate change on water availability in the Volta Basin of West Africa, in: IAHS Publication No. 295 "Regional Hydrological Impact of Climate variability and Change", 75-85, 2005.

Liebe, J., van de Giesen, N., and Andreini, M.: Estimation of small reservoir storage capacities in a semi-arid environment - A case study in the Upper East Region of Ghana, Phys. Chem. Earth, 30(6-7), 448-454, 2005.

McKnee, T. B., Doesken, N. J., and Kleist, J.: The relationship of drought frequency and duration to time scales, 8th Conference on Applied Climatology, 179-184, Anaheim, California, USA, 1993.

Taylor, J. C., van de Giesen, N., and Steenhuis, T.: West Africa: Volta discharge data quality assessment and use, J. Am. Water Resour. Assoc., 42(4), 1113-1126, 2006.

United Nations Development Program: Human Development Report 2007/2008, http://hdr.undp.org/en/media/HDR_20072008 EN_Complete.pdf, 2007.

Van de Giesen, N., Andreini, M., van Edig, A., and Vlek, P.: Competition for water resources in the Volta basin, IAHS Publ. no. 268, 2001. 